\title{
PELATIHAN TEKNIK PENGOLAHAN DAN PERLUASAN PASAR MELALUI INOVASI PRODUK OLAHAN BERBAHAN DASAR LABU KUNING (WALUH) DI KELURAHAN BANJARSARI KECAMATAN NUSUKAN SURAKARTA
}

\author{
Dra. Murni Sulistyowati, MM ${ }^{1)}$, Endang Sri Suwarni, SH, MH ${ }^{2)}$ \\ ${ }^{1,}$ Dosen Manajemen STIEAUB Surakarta \\ ${ }^{2,}$ DosenAkuntansi STIEAUB Surakarta \\ Jl. Mr. Sartono 97Cengklik, Nusukan. Surakarta. \\ e-mail : ${ }^{1)}$ murni_sulistyowati@yahoo.com ${ }^{2)}$ endangss@gmail.com
}

\begin{abstract}
Devotion to the Community activity on topic about Training on Processing Techniques and Market Expansion Through Innovation in Processed Products Made from Pumpkin at Kelurahan Nusukan Kecamatan Banjarsari Surakarta targeted by craftsmen and The Family Welfare community. The purpose of this devotion activity is to provide counseling and training on the processing and market expansion techniques of pumpkin based products at Bibis Baru Kelurahan Nusukan Kecamatan Banjarsari Surakarta. The method used in this Devotion activity is the lecture method on the processing and packaging techniques of sweet potato based products so that the participants are the craftsmen group and The Family Welfare community can directly engage in practice and creating utilize sweet potato to become food products with the look and taste that tempting the taste, As well as worth selling so that it can increase family income and develop into a promising business in the future. The target after the training is quite encouraging $60 \%$ of the training objectives are achieved and the rest needs to be followed up with mentoring for subsequent CommunityService.
\end{abstract}

Keywords :pumpkin, processing and market expansion. food product

\begin{abstract}
Abstraksi
Kegiatan Pengabdian Kepada Masyarakat dengan topik tentang Pelatihan Teknik Pengolahan dan perluasan Pasar melalui Inovasi Produk Olahan Berbahan Dasar Labu kuning (waluh) di Kelurahan Nusukan Kecamatan Banjarsari Surakarta dengan sasaran kelompok pengrajin dan Ibu-ibu PKK. Tujuan kegiatan pengabdian ini adalah memberikan penyuluhan dan pelatihan tentang teknik pengolahan dan perluasan pasar produk olahan berbahan dasar labu kuning (waluh) di Kelurahan Nusukan Kecamatan Banjarsari Surakarta. Metode yang digunakan dalam kegiatan Pengabdian ini adalah metode ceramah tentang teknik pengolahan dan perluasan pasar produk olahan berbahan dasar labu kuning (waluh) agar para peserta yaitu kelompok pengrajin dan Ibu-ibu PKK dapat langsung terlibat berlatih dan berkraeasi memanfaatkan ubi menjadi produk makanan dengan tampilan dan rasa yang menggoda selera, serta layak jual sehingga dapat meningkatkan pendapatan keluarga dan berkembang menjadi usaha yang menjanjikan pada masa mendatang. Target setelah dilaksanakan pelatihan cukup menggembirakan $60 \%$ tujuan pelatihan tercapai dan sisanya perlu ditindak lanjuti dengan pendampingan untuk Pengabdian Kepada Masyarakat berikutnya.
\end{abstract}

Kata kunci :

Pumpkin, pengolahan dan perluasan pasar, Produk Olahan

\section{PENDAHULUAN}

Surakarta, kota yang lebih populer dengan sebutan kota Solo (Sala) secara geografis berada pada suatu dataran rendah yaitu pada cekungan lereng pegunungan Lawu dan pegunungan Merapi dengan ketinggian kurang lebih $92 \mathrm{~m}$ di atas permukaaan air laut, berbatasan dengan beberapa kabupaten yang 
ternasuk dalam eks Karesidenan Surakarta seperti

Kabupaten Klaten, Wonogiri, Boyolali,

Sukoharjo, Sragen Dan Karanganyar. Menilik sejarah kota Solo atau Sala yang merupakan kota terbesar ketiga di Jawa bagian selatan setelah Bandung dan Malang, merupakan pewaris kesultanan Mataram yang dipecah melalui perjanjian Giyanti pada tahun 1755 bersama kota Yogyakarta. Kemakmuran dan kemashuran kota Surakarta sejak dulu sampai kini, hingga terabadikan dalam satu lagu keroncong yang sangat populer "Bengawan Solo" karya besar sang legendaris maestro keroncong Gesang.Kota yang memiliki semboyan mulat sarira angrasa wani dan slogan umum berseri (akronim bersih sehat rapi indah) serta slogan pariwisata The spirit of Java ini memiliki luas wilayah $44 \mathrm{~km}^{2}$ terdiri dari 5 kecamatan dan 51 kelurahan dengan jumlah penduduk mencapai 503.421 jiwa (sumber: wikipedia th.2010) dan tingkat kepadatan penduduk tertinggi di Jawa Tengah yaitu $11.370 \mathrm{jiwa} / \mathrm{km}^{2}$ ( kepadatan Jawa Tengah hanya 992 jiwa $/ \mathrm{km}^{2}$. Banyak julukan diberikan pada kota Solo, sebagai kota sejarah, kota budaya, kota pendidikan, kota terbersih dengan meraih penghargaan Adipura beberapa kali, kota pariwisata dan kota dagang/ pusat bisnis (sejarah mencatat lahirnya Sarikat Dagang Islam di Indonesia di kota Solo), kota dengan tingkat pertumbuhan ekonomi tinggi dan menjanjikan untuk tujuan investasi. Terbukti beragam industri tumbuh pesat. Solo juga dikenal sebagai surga kuliner dan menjadi destinasi wisata kuliner bagi wisatawan domestik maupun mancanegara, keragaman serta kekhasan cita rasa makanannya mampu memanjakan lidah para penikmat rasa. Kelurahan Nusukan Kecamatan Banjarsari
Surakarta merupakan salah satu wilayah utara Surakarta yang berbatasan dengan Kabupaten Karanganyar dan Kabupaten Boyolali, dengan komposisi peduduk 49,4\% laki-laki dan 50,6\% perempuan, mayoritas mata pencaharian penduduk adalah buruh kurang lebih 30,77\%, tingkat pendidikan terbanyak lulus SLTA 34,5\%, dan mayoritas beragama Islam 90,86\% dan $62,4 \%$ adalah usia produktif ( Laporan Monografi Dinamis Kelurahan Nusukan Kecamatan Banjarsari bulan Agustus 2016).

Terjaidi kontradiksi, jika kita mencermati dan menganalisis situasi kondisi warga Kelurahan Nusukan yang mayoritas berada pada golongan usia produktif $(62,4 \%)$, semestinya membawa kita berpikir positif karena berkaitan dengan pendapatan yang diterima per Kepala Keluarga untuk memenuhi berbagai kebutuhan hidup sehari-harinya. Namun apabila dilihat dari prosentase mata pencahariannya $42,54 \%$ menengah ke bawah ( petani, buruh dan pedagang kecil dan menengah) sebesar maka ini berarti masih banyak penduduk dengan pendapatan minimal sampai tingkat UMR. Pada situasi dan kondisi seperti inilah, para istri /ibu-ibu warga Kelurahan Nusukan mengambil peran aktif dalam upaya membantu menambah pendapatan keluarga, mereka berusaha bekerja berbekal pendidikan dan ketrampilan seadanya, ada yang menjadi penjahit borongan atau mencoba berjualan berkeliling. Namun upah yang mereka terima terlalu kecil membuat mereka berusaha mencari terobosan lain dengan menjadi pemetik dan penyortir lombok/cabe untuk dipasok ke bebeapa perusahaan sambal saus botol. Namun itu ternyata tak berberlangsung lama dan mereka nilai kurang menjanjikan karena ketidak stabian 
harga dan pasokan lombok/cabe sehingga mereka kembali mencoba berjualan warungan atau membuar beberapa kue dan makanan untuk disetorkan dan dijual di warung atau wedangan angkringan yang penghasilannya tidak cukup memadai untuk menopang kebutuhan sehari-hari yang makin tinggi seiring mahalnya biaya hidup dan biaya pendidkan anak yang makin tinggi.

Sebagaimana disebutkan di atas , Solo dikenal sebagai surganya kuliner dan melimpahnya produk pertanian dari beberapa kabupaten sekitar Surakarta menginspirasi Tim Pengabdian Kepada Masyarakat untuk menawarkan solusi setelah melalui pengamatan situasi, mendengarkan keluhan dan keinginan ibu-ibu PKK dan Kelompok Usaha Rumahan (home industry) untuk bangkit memperbaiki kondisi ekonomi keluarganya, tidak tau harus membuat dan menjual produk makanan apa yang cukup menjual (madolke dalam bahasa Jawa). Pepatah mengatakan Gayung pun bersambut, ibu-ibu PKK dan kelompok industri rumahan antusias menyambut uluran tangan kami Tim pengabdian Kepada Masyarakat.

Berangkat dari analisis situasi itulah Tim Pengabdian Kepada Masyarakat menawarkan solusi untuk mengolah aneka produk makanan berbahan dasar produk pertanian lokal seperti ubi ungu dan kuning, ketela pohon (singkong/ ubi kayu/ pohong/ cassava/ manihot osculenta/ manihot utilissima), jagung, kentang, talas dan labu kuning atau dikenal dengan sebutan waluh, yang banyak dijumpai di pasar tradisional dan harganya cukup murah menjadi produk makanan bergizi, bercita rasa, sederhana bahan, alat dan proses pembuatannya agar bisa tampil lebih enak, mewah, cantik dan menarik serta bernilai ekonomis sehingga diharapkan bisa menambah pendapatan keluarga dengan tetap melestarikan bahan-bahan olahan alami hasil produksi lokal. Labu kuning (waluh) merupakan salah satu jenis produk pertanian yang mampu bertahan agak lama ini, telah menginspirasi kami Tim pengabdian Kepada Masyarakat untuk mencari solusi tepat pengolahannya.

Bentuk kegiatan pengabdian ini adalah penyuluhan dan pelatihan dengan peragaan atau demo /praktik kepada ibu-ibu PKK dan Kelompok Usaha Rumahan untuk mengolah bahan dasar labu kuning (waluh) yang dipadukan dengan bahan dasar lain mejadi aneka produk olahan yang lebih variatif dan tampil berbeda menjadi kue moderen (cake dan pastry) dan kue kering seperti soes kering, stick ataupun kue basah seperti brownies, sponge cake, chiffon cake , pie, talam, kue lumpur, cup cake, muffin, bolu kukus, putu ayu dan kreasi kue berbahan labu kuning (waluh) lainnya. Kegiatan ini diharapkan berhasil membuka peluang usaha yang menjanjikan pada khalayak sasaran.

\section{METODE}

Berdasarkan survei dan pengamatan Tim Pengabdian Kepada Masyarakat setelah melakukan analisis situasi pada masyarakat khususnya pada Ibu-ibu PKK dan sekelompok usaha rumahan (home industry) di Bibis Baru Kelurahan Nusukan Kecamatan Banjarsari Surakarta yang menanyakan bagaiamana mengolah, mengemas dan memasarkan produk makanan berbahan dasar labu kuning ( waluh) agar tidak monoton, lebih variatif, bernilai gizi, tampil dalam sajian dan kemasan yang lebih cantik dan menarik serta bernilai ekonomis lebih 
tinggi,maka kegiatan Pengabdian Kepada

Masyarakat ini dilaksanakan dalam bentuk sebagai berikut :

\section{Presentasi}

Memberikan ceramah dan penyuluhan tentang kandungan gizi yang terdapat pada berbagai jenislabu kuning (waluh), bagaimana teknik pengolahan dan pengemasan produk makanan berbahan dasar labu kuning (waluh)sehingga lebih variatif, menarik, dan bernilai ekonomis tanpa mengurangi kandungan gizi dan manfaatnya kepada ibu-ibu PKK dan kelompok usaha rumahan (home industry) di Bibis Baru Kelurahan Nusukan Kecamatan Banjarsari Surakarta.

\section{Peragaan dan Pembagian alat /bahan.}

Memperagakan, mempraktikkan dan memberikan pelatihan kepada Ibu-ibu PKK dan kelompok usaha rumahan (home industry) bagaimana mengolah produk labu kuning (waluh) menjadi aneka produk makanan yang lebih variatif, bergizi dan bercita rasa tinggi dengan tampilan yang lebig cantik dan menarik serta dikemas dalam kkemasan yang higienis dan menarik sehingga diharapkan mampu meningkatkan nilai jual dan ekonomis produk olahan tersebut. Labu kuning (waluh) yang biasanya hanya diolah menjadi produk makanan yang terkesan tradisional dan hanya dikenal lokal sepertilabu kuning kukus, kolak, bubur, lemet dan talam labu kuning ( waluh) dan sejenisnya kini saatnya dikembangkan dengan kreativitas dan lebih variatif menjadi olahan kue cantik dan bercita rasa serta bernilai jual dan ekonomis yang tinggi baik kue kering maupun kue basah. Aneka kue kering berbahan dasar labu kuning (waluh) misal nastar, kaastangel, soes kering, stick dan sebagainya. Sedangkan kue basah berbahan dasar labu kuning (waluh) misalnya brownies , soes, puding, soup, puree, aneka roti, spong cake /bolu, chiffon cake , donat, kue lumpur,cup cake, muffin, pancake, kue ku,dan sebagainya. Selanjutnya memperagakan bagaimana nenyajikan, pengemasannya dan strategi pemasaran dan perluasan pasarnya.

\section{HASIL PEMBAHASAN DAN DAMPAK}

\section{Teknik Pengolahan Produk makanan} Berbahan Dasar Labu Kuning (waluh)

Sampai saat ini banyak kita jumpai pada mayoritas masyarakat Indonesia, pengolahan, penyajian dan pengemasan produk makanan berbahan dasar labu kuning (waluh) di kalangan ibu-ibu PKK dan kelompok usaha rumahan (home industry) maupun masyarakat pada umumnya hanya dlakukan secara sederhana, diolah ala kadarnya menjadi makanan lokal demikian pula penyajian dan pengemasannya pun terkesan dilakukan ala kadarnya, sehingga kurang variatif , kurang menarik dan membosankan,padahal sesungguhnya dengan sedikit kreasi dan inovasi dapat menjadi bahan dasar untuk diolah menjadi beragam kue yang enak, bernilai gizi tinggi dan menarik. Oleh karena itu Tim Pengabdian tergerak hati untuk turun tangan membantu Ibu-ibu PKK dan Kelompok Usaha Rumahan (home industry) di Bibis Baru mengembangkan kreativitas dan inovasi dalam mengolah, menyajikan dan mengemas aneka produk makanan berbahan 
dasar labu kuning (waluh) agar lebih variatif, menarik dan bernilai ekonomis.

Kami Tim Pengabdian Kepada Masyarakat (PKM STIE AUB Surakarta menawarkan beberapa kegiatan Pengabdian Kepada Masyarakat sebagai berikut :

a. Memberikan peragaan /praktik dan pelatihan teknik mengolah aneka produk makanan berbahan dasar labu kuning (waluh) menjadi kue-kue yang enak, bergizi, bernilai ekonomis dengan performa lebih variatif, cantik dan menarik.

b. Memberikan pelatihan teknik penyajian dan pengemasan aneka produk makanan berbahan dasar labu kuning (waluh) agar penampilan , penyajian dan pengemasannya bertahan lebih lama dan menarik.

Produk Makanan berbahan dasar labu kuning (waluh) saat ini mulai banyak dilirik, karena lembut, legit dan indahnya cara penyajian. Sebelumnya barangkali orang kurang tertarik dan berminat mencobanya, namun faktanya kini kue, snack, roti, pastry dan banyak makanan olahan berbahan dasar labu kuning (waluh) banyak diminati, tidak jarang ada pula yang terus mencoba dan bereksperimen mengembangkan usaha nya di bidang kuliner, sekadar nguri-uri kebudayaan agar tidak punah digerus masuknya makanan cepat saji dari luar melalui kuliner hingga terus berinovasi dan memodifikasikan aneka produk makanan berbahan dasar labu kuning (waluh) berbagai varian. Antara lain pengolahan labu kuning(waluh) diklasifikasikan menjadi dua sebagai berikut : a. Produk olahan makanan klasifikasi tradisonal/ klasik, seperti : bubur (puree), kue lumpur, aneka soup dikombinasikan dengan bahan lain, kue talam, putu mayang, bakpia dan kolak

b. Produk olahan makanan klasifikasi modifikasi seperti aneka roti, cake dan pastry seperti roti manis, brownies, donat, pastry, pie, cup cake, bolu gulung, soes, chiffon cake, sponge cake, dan aneka kue kering nastar, kastengel, egg roll, stick dan lain-lain.

Pada kegiatan ini, kami Tim Pengabdian Kepada Masyarakat memperagakan dan mengajarkan beberapa jenis produk makanan olahan berbahan dasar labu kuning (waluh) kepada kelompok pengrajin dan ibu-ibu PKK Bibis Baru Kelurahan Nusukan kecamatan Banjarsari Surakarta, seperti produk makanan olahan tradisonal kue lumpur berbahan dasar labu kuning (waluh) dan produk makanan olahan modifikasi bolu gulung (roll cake), cup cake, brownies (kukus dan panggang), chiffon cake dan kue soes vla.

2. Teknik Perluasan Pasar melalui Inovasi Produk Olahan Berbahan dasar Labu Kuning (waluh)

Sesi akhir dari kegiatan Pengabdian Kepada Masyarakat Tim Pengabdian Kepada Masyarakat STIE AUB Surakarta ini adalah memberikan pengetahuan berupa pelatihan teknik pemasaran dan perluasan pasar melalui inovasi produk olahan berbahan dasar labu kuning (waluh) hasil pelatihan teknis pengolahan makanan berbahan dasar labu kuning (waluh) yang telah selesai Tim berikan kepada kelompok pengrajin dan Ibu-ibu PKK 
Bibis Baru Kelurahan Nusukan Kecamatan

Banjarsari Surakarta.

Pelatihan teknis terdahulu Tim telah memberikan pelatihan teknis mengenai teknis pengemasan produk makanan olahan yang baik dan higienis, sehingga produk makanan olahan lebih terlindung, awet dan dengan tampilan yang cantik dan menarik . Dengan pengemasan yang baik, higienis dan menarik diharapkan mampu menaikkan nilai ekonomis atau nilai jual produk makanan olahan tersebut. Selain kemasan yang baik, higienis dan menarik kami Tim Pengabdian Kepada Masyarakat juga membekali tentang prosedur pengajuan merk dagang untuk legalitas usaha yang dijalankan serta untuk tujuan pembedaan dari produk yang dihasilkan oleh pesaing.

Pada kesempatan ini Tim Pengabdian Kepada Masyarakat STIE AUB Surakarta menambahkan pengetahuan mengenai teknis perluasan pasar. Diharapkan nantinya khalayak sasaran yaitu ibuibu PKK dan Kelompok Pengrajin di Kelurahan Nusukan Kecamatan Banjarsati dapat lebih luas memasarkan produknya tidak hanya sebatas lingkungan Kelurahan akan tetapi mampu menembus pasar wilayah Surakarta dan sekitarnya bahkan pasar regional Jawa Tngah melalui inovasi produk olahan berbahan dasar labu kuning (waluh).

Inovasi produk olahan yang Tim tawarkan pada kegiatan Pengabdian Kepada Masyarakat kali ini adalah dengan pembuatan kue kering naastar, kaastangel dan stick berbahan dasar labu kuning (waluh), karena kue kering jenis ini sederhana dan mudah pembuatannya, lebih tahan la lebih tahan lama dibandingkan kue basah sehingga diharapkan bisa dipasarkan di pasar yang lebih luas dan banyak digemari oleh sebagian besar masyarakat terlebih pada masa-masa tertentu seperi hari raya.

Pada akhirnya nanti diharapkan kue kering berbahan labu kuning (waluh) menjadi menjadi produk unggulan khalayak sasaran dan menjadi oleh-oleh khas yang pantas rindukan oleh konsumen /tamu yang berkunjung ke kota Solo (Surakarta).

\section{DAMPAK}

Peningkatan kesejahteraan dapat dirasakan oleh keluarga dengan adanya tambahan pendapatan dengan menerapkan pelatihan ini dalam usaha rumahan (Home Industry)

\section{KESIMPULAN DAN SARAN}

\section{Kesimpulan}

Berdasarkan analisis situasi, permasalahan yang ada pada sasaran (kelompok pengrajin dan usaha rumahan serta ibu-ibu PKK) di Kelurahan Nusukan Kecamatan Banjarsari Surakarta serta hasil pelaksanaan pelatihan teknik pengolahan dan pengemasan produk makanan berbahan dasar labu kuning (waluh) Kelurahan Nusukan Kecamatan Banjarsari Surakarta , maka dapat disimpulkan :

a. Kelompok pengrajin, usaha rumahan dan Ibu-ibu PKK Kelurahan. Nusukan Kecamatan Banjarsari Surakarta sangat antusias mengikuti pelatihan teknik pengolahan dan pengemasan produk makanan berbahan dasarlabu kuning (waluh), hal ini dapat dilihat dari semangat mereka berlatih melakukan tahap demi tahap dalam proses pembuatan beberapa jenis produk olahan berbahan dasar labu kuning (waluh) yang Tim berikan dan banyaknya pertanyaan yang mereka ajukan.

b. Kelompok pengrajin dan Ibu-ibu PKK Bibis Baru Kelurahan Nusukan Kecamatan Banjarsari 
Surakarta sangat antusias mengikuti penyuluhan dan pelatihan teknik perluasan pasar melalui inovasi produk olahan berbahan dasar labu kuning (waluh) dan berharap ada pendampingan dari Tim

PKM STIE AUB Surakarta

\section{Saran}

a.Pada kegiatan Pengabdian Kepada Masyarakat berikutnya disarankan agar tidak hanya perwakilan setiap RW saja, tetapi setiap RT atau dasa wisma agar lebih mengenai sasaran.

b.Pada kegiatan Pengabdian Kepada Masyarakat yang akan datang disarankan agar dikembangkan dengan menggunakan bahan dasar lain yang belum diolah maksimal tetapi melimpah dan memiliki kandungan gizi serta manfaat besar bagi kesehatan dan lingkungan, seperti jenis talas dan lainnya.

c.Kegiatan Pengabdian Kepada Masyarakat ini disarankan tidak berhenti hanya sampai disini saja, tetapi ada tindak lanjut nyata sehingga terjalin kerjasama yang berkesinambungan antara Tim Pengabdian Kepada Masyarakat dengan Kelompok Pengrajin dan Ibu-ibu PKK serta bisa merangkul para pengusaha besar sebagai sasaran pelaksana dan menjadi orang tua angkat bagi kelompok pengrajin kecil hingga menengah melalui program Corporate Social Responsibility (CSR).

d.Kegiatan Pengabdian Kepada Masyarakat yang akan datang dapat dikembangkan pada ide-ide kreatif dan inovatif lainnya, dengan memanfaatkan bahan alam maupun limbah menjadi produk yang bisa diandalkan dan layak jual.

\section{DAFTAR PUSTAKA}

Jurnal,untad.ac.id>article>download ; Retensi Karoten Dalam Berbagai ProdukOlahan Labu Kuning (Cucurbita Moschata Durch)
Lupiyoadi R, (2011), Managemen Pemasaran, Jakarta: Jasa Asalembaa Empat

Suherman (2005) Ekonomi mikro, Jakarta: Rineka Jaya

Titik P, (2005), Gizi Masyarakat, Jakarta: Gramedia

Tjipto Fandi, (2008), Pemasaran Strategik, Bandung: Andi Publisher

http://google,weblight .com

https://cookpad.com>cari>labukuning

https://id.m.wikionary.org>wiki>waluh

http://id.m.wikipedia.org >wiki>waluh

https://id.glosbe.com>waluh

https://www.kompasiana.com>imizona

https://mirzaherawati.wordpress.com

https://www,sukowaspodo.blogspot.co.id

https://www, vemale.com>resep-makanan

kbbi.co.id>arti kata>waluh

Kompasiana, Kompas 6 September2014

m.bisnis.com> labu kuning> Peluang Usaha 